\title{
Synergistic effect of chitosan derivative and DOPO for simultaneous improvement of flame retardancy and mechanical property of epoxy resin
}

\section{Junjie Wang}

Wuhan Institute of Technology

\section{Xuejun Yu}

Three Gorges Public Inspection and Testing Center

Shengsong Dai

Wuhan Institute of Technology

\section{Xinyu Wang}

Wuhan Institute of Technology

\section{Zhiquan Pan}

Wuhan Institute of Technology

Hong Zhou ( $\nabla$ hzhouh@126.com )

Wuhan Institute of Technology https://orcid.org/0000-0003-2409-784X

\section{Research Article}

Keywords: Epoxy resin, Chitosan derivative, DOPO, Flame retardancy, Mechanical properties.

Posted Date: July 12th, 2021

DOl: https://doi.org/10.21203/rs.3.rs-621453/v1

License: (1) This work is licensed under a Creative Commons Attribution 4.0 International License.

Read Full License

Version of Record: A version of this preprint was published at Cellulose on November 24th, 2021. See the published version at https://doi.org/10.1007/s10570-021-04261-3. 


\section{Abstract}

In this work, the effects of a chitosan-based derivative (CSA), DOPO and CSA-DOPO additives on the flammable properties of EP composites were systematically studied, where CSA was synthesized by a facile condensation between chitosan (CS) and 9-anthralaldehyde and. DOPO was 9, 10-dihydro-9-oxa10- phosphaphenanthreene-10-oxide. The mass ratio of CS and 9-anthralaldehyde in CSA was determined by elemental analysis and theoretical calculation, which matched well with each other. Under the 8\% addition in EP, EP/2.66\%/5.34\%DOPO sample was the only one, which passed the UL-94 rating and exhibited the highest LOI value of $36.4 \%$. Compared with EP, the cone calorimeter test (CC) showed that the total smoke emission value and the peak heat release rate of the CSA and DOPO modified EP decreased $36.0 \%$ and $61.9 \%$, respectively, and the residual char amount increased by $151 \%$. The possible flame retardant mechanism of CSA/DOPO towards EP was proposed according to the results of the real time FTIR spectra at different pyrolysis temperatures, cone calorimeter and Py-GC/MS analysis for EP and EP/2.66\%CSA/5.34\%DOPO samples, and Raman spectra and XPS for their char residues. Moreover, the incorporation of CSA/DOPO effectively improved the mechanical properties, especially, the flexural strength was increased by $52.3 \%$. It was proposed that CSA/DOPO plays roles in both vapor and condensed phases, and the synergistic effect of CSA and DOPO significantly improve the flame retardancy and mechanical strength of EP.

\section{Introduction}

Epoxy resin has been frequently used in many fields owing to its superior chemical resistance, excellent adhesion and good mechanical properties (Zhu et al. 2020; Tang et al. 2019; Yu et al. 2016). However, the widespread use of epoxy resin is severely limited due to its own flammability (Jin et al. 2019). In order to increase the fire resistance of epoxy resin materials, adding flame retardants in EP is considered as the most direct, efficient and economical method (Zhu et al. 2019).

Due to the flame retardancy function of DOPO in both gas and condensed phases, much work has been performed to synthesize DOPO-based derivatives for the purpose of upgrading the flame retardancy of EP (Selmera et al. 2015). The preparation of DOPO-based derivatives is usually based on the chemical reactions between P-H bond in DOPO and active groups in other substances. Some of the derivatives exhibited excellent flame retardancy toward EP. For examples, Carja and co-workers (Carja et al. 2014) synthesized the oligomer DOPO-PFR using DOPO, rterephthalaldehyde and phenylphosphonyl dichloride as raw materials. When DOPO-PFR with the phosphorus content of 2 and $3 \%$ were added to EP system, the obtained epoxy matrix can reach UL-94 V-0 rating. Wang Xin et al. (Wang et al. 2010, 2011a, b, c, d) used phosphorus oxychloride, pentaerythritol and DOPO-based dihydric phenolic compounds as raw materials to synthesize a series of DOPO-based oligomers. When these oligomers were added in EP using 4, 4'-diaminodiphenylmethane as a curing agent, the amount of combustible gas, the total heat release and the maximum heat release rate in the combustion process were reduced significantly, and the LOI value was greatly increased. Yang Shuang et al. (Yang et al. 2015) used N-(4-hydroxyphenyl) maleimide and cyanuric chloride to synthesize a maleimide functional group-containing triazine 
derivative TMT, and then reacted it with DOPO to synthesize the flame retardant DOPO-TMT. When the phosphorus content is $1.0 \mathrm{wt} \%$, the LOI value of the modified EP reached $36.2 \%$ and passed the UL-94 V-0 test. Although some DOPO-based derivatives modified EP composites exhibited good flame retardancy, the complicated preparation process as well as the drawbacks in mechanical properties limited their industrial application. Easy preparation with lower cost and good mechanical properties is still the essential conditions for large scale production of EP. Aurelio Bifulco et al. (Aurelio et al. 2020) modified epoxy resin with the combined action of a DOPO-derivative, melamine and silica, the obtained epoxy resin composite achieved UL 94-V-0 classification at low P-content (2.0 wt\%). The better flame retardancy of EP composites promoted by the combined action of several substances was worth to further study for industrial applications.

As a natural polysaccharide biomass polymer material (Dash et al. 2011; Yang et al. 2018), chitosan (CS) can be used as a charring agent due to the abundant hydroxyl groups in its structure (Chen et al. 2016). However, it has the disadvantages of low initial decomposition temperature, poor thermal stability and low flame retardant efficiency (Prabhakar and Jung-il 2018; Hu et al. 2012). The amine groups and hydroxyl groups possessed by chitosan can be used as active groups for chemical modification (Hirano et al. 2003; Huang et al. 2011). The salicylaldehyde modified chitosan combined with polyphosphate with the total content of $25 \%$ in polyurethane exhibited better flame retardancy (Liu et al. 2017). Chitosan derivative modified by gradually grafting $\mathrm{PO}(\mathrm{OH})_{2}$ and melamine and organic montmorillonite were used as an intumescent flame retardant (IFR) for EP (Yu et al. 2020a, b). There were some examples of chitosan as a flame retardant component of epoxy resins. Rao Tentu Nageswara et al. (Rao et al. 2019) reported that the introduction of $\mathrm{ZrO}_{2} \mathrm{NPs}$, chitosan, boric acid, ammonium polyphosphate and melamine into EP can increase the LOI value and reach UL-94 V-0 rating, significantly. However, the flame retardants derived from CS were rarely reported due to its lower reaction activity. In our previous work, a flame retardant (CCD) was synthesized by two-step chemical reaction using chitosan, cinnamaldehyde and DOPO as raw materials, CCD exhibited better flame retardancy (Chen et al. 2020). We have also tried to synthesize other DOPO modified chitosan, however, it was difficult to get the designed products. It may be the reason why no other reports of DOPO-chitosan modified chitosan were found in literature.

Based on the charring function of chitosan derivative and the flame retardancy of DOPO, a Schiff base compound CSA was prepared by the condensation between the active amine groups of chitosan and aldehyde of 9-anthralaldehyde. The effects of different dosages of CSA and DOPO in EP on the combustion and mechanical properties of EP composites were studied, and the possible flame retardant mechanism of CSA/DOPO was proposed based on the results of TG-FTIR, cone calorimeter, Raman spectra, XPS and Py-GC/MS analysis. The superior properties of EP/2.66\%CSA/5.34\%DOPO in both flame retardancy and mechanical properties has not been found in chitosan containing flame retardants for EP. Moreover, the as prepared EP composites have the advantages of facile preparation, lower cost and improved flame retardancy and mechanical properties.

\section{Experimental}




\subsection{Materials}

DOPO (98.5\%) and epoxy resin (DGEBA, E-44) were provided by Huangshi Hongsheng Reagent Co., Ltd, Huangshi, China. Diamino diphenylmethane (DDM), tetrahydrofuran (97\%) and methanol (99.5\%) were purchased from Sinopharm Chemical Reagent Co., Ltd, Shanghai, China. Chitosan (Deacetylation degree $\geq 95 \%$ ) and 9-anthracene aldehyde (99\%) were obtained from Macklin reagent Co., Ltd, Shanghai, China.

\subsection{Synthesis of CSA}

The CSA was synthesized according to the literature method with some modifications (Kumar et al. 2009), the synthetic route was shown in Fig. 1a. First, chitosan $(8.06 \mathrm{~g}, 0.05 \mathrm{~mol})$ was dispersed in 150 $\mathrm{ml}$ methanol in a three-necked flask equipped with a condenser. A mixture of 9-anthralaldehyde $(20.73 \mathrm{~g}$, $0.1 \mathrm{~mol}$ ) and $150 \mathrm{ml}$ of tetrahydrofuran was added dropwise through a constant pressure funnel within 60 minutes. The resulting mixture was heated to $75^{\circ} \mathrm{C}$ and refluxed for 12 hours. Then it was cooled and filtered. The obtained filter cake was washed three times with a mixture of methanol and tetrahydrofuran (volume ratio 1:1). Finally, the product was dried at $60^{\circ} \mathrm{C}$ for 6 hours under vacuum.

\subsection{Preparation of EP mixtures}

The preparation process of CSA/DOPO flame-retardant epoxy resin material was as follows (Fig. 1b): Firstly, DGEBA and CSA (or CS) were mixed uniformly in a two-necked flask. After it was heated under vacuum at $130{ }^{\circ} \mathrm{C}$ for about 40 min, a translucent liquid was obtained. Then, DOPO was added in a certain mass ratio, and stirred to get homogeneous. DDM was added under vigorous stirring and vacuum condition after the temperature dropped to $95^{\circ} \mathrm{C}$. Finally, the mixture was poured into the clean mold, cured for 2 hours at $100{ }^{\circ} \mathrm{C}$ and another 2 hours at $150^{\circ} \mathrm{C}$. The compositions of the modified EP samples were listed in Table 1.

\subsection{Methods}

FTIR spectra of CS, CSA and the char residue for EP/2.66\%CSA/5.34\%DOPO were recorded on a Thermo Nicolet 5700 FTIR spectrophotometer using the KBr disk in a wavenumber range of $4000-400 \mathrm{~cm}^{-1}$.

The contents of carbon, hydrogen and nitrogen in CS and CSA were analyzed by a Vario MACRO cube elemental analyzer and phosphorus content in the char residue of EP/2.66\%CSA/5.34\%DOPO was detected additionally.

The surface morphologies studies of the char residual were performed on JEOL JSM-5900LV under vacuum at an acceleration voltage of $20 \mathrm{kV}$.

The thermal decomposition behavior of CS, CSA and epoxy resin thermosetting polymer samples were recorded by a thermogravimetric analyzer (NETZSCH STA449F3). The test was conducted by heating from $30^{\circ} \mathrm{C}$ to $790^{\circ} \mathrm{C}$ under nitrogen. The heating rate was $10^{\circ} \mathrm{C} / \mathrm{min}$. 
The LOI value was obtained on a JF-3 oxygen index instrument, the sample size was $130 \times 6.5 \times 3.2$ $\mathrm{mm}^{3}$. The UL-94 rating was measured with the sample size $130 \times 13 \times 3.2 \mathrm{~mm}^{3}$. The cone calorimeter (CC) test was carried out according to standard ISO 5660 with the sample size of $100 \times 100 \times 3.2 \mathrm{~mm}^{3}$ under an external heat flux of $50 \mathrm{~kW} / \mathrm{m}^{2}$.

X-ray photoelectron spectra of the char residues left behind after cone calorimeter tests were recorded on an ESCALAB 250xi (America) using AlKa radiation (1486.6 eV) as an excitation source.

Raman spectroscopy was recorded on LabRAMHR800 laser Raman spectrometer to characterize the types of the carbon under $532 \mathrm{~nm}$ helium-neon laser line at room temperature.

Pyrolysis products of EP composites were analyzed by Py-GC/MS in helium atmosphere. Firstly, the sample was pyrolyzed in a cracker (CDS 5200) at $600^{\circ} \mathrm{C}$, and then the volatile products were transported to the Perkin-Elmer Clarus 680 GCSQ8MS gas chromatography-mass spectrometer via helium.

The flexural and tensile tests of the samples were recorded on CMT4104 universal testing machine (SANS) with a dumbbell shape of $75 \times 4 \times 2 \mathrm{~mm}^{3}$ and a rectangle of $80 \times 10 \times 4 \mathrm{~mm}^{3}$, separately, according to the standard of GB/T 9341-2008 and GB/T 1040.2-2006. Five samples were measured each time, and the average value was taken.

TG-FTIR was used to analyze the FTIR spectra of the gas components from the TGA, and the real time FTIR analysis of the pyrolysis gases was conducted on a Thermo Fisher IS50, the transfer line of gases from TGA to FTIR was heated at $280^{\circ} \mathrm{C}$.

\section{Results And Discussion}

\subsection{Characterization of CSA}

Fig. 2 shows the FTIR spectra of chitosan and CSA. For chitosan, there is a wide frequency band in the range of 3400-3800 $\mathrm{cm}^{-1}$, which was due to the stretching vibration of the $\mathrm{O}-\mathrm{H}$ bond and the $\mathrm{N}-\mathrm{H}$ bond, while the peak centered at $2907 \mathrm{~cm}^{-1}$ was assigned to the $\mathrm{C}-\mathrm{H}$ bond. There were two obvious characteristic peaks at $1157 \mathrm{~cm}^{-1}$ and $1602 \mathrm{~cm}^{-1}$, which were attributed to the tensile vibration of the sugar structure and amino groups, respectively. For CSA, a new stretching vibration absorption peak at $1645 \mathrm{~cm}^{-1}$ was detected, which was attributed to $-\mathrm{C}=\mathrm{N}$ (Dubey et al. 2018), indicating the existence of Schiff base in CSA. It was noted that there was no aldehyde characteristic peak appeared at about 1680 $\mathrm{cm}^{-1}$, revealing that CSA did not contain unreacted 9-anthralaldehyde.

The chemical composition of CSA was further characterized by elemental analysis. According to the $\mathrm{C}, \mathrm{N}$ and $\mathrm{H}$ atomic contents of CS and CSA in Table S1, the $\mathrm{C}$ contents in CS and CSA were $44.58 \%$ and 68.04 $\%$, respectively. Compared with CS, $\mathrm{H}$ and $\mathrm{N}$ contents in CSA decreased by 1.13 and $3.55 \%$, respectively. The reason for the increase of $\mathrm{C}$ content and the reduction of $\mathrm{H}$ and $\mathrm{N}$ contents can be attributed to the introduction of nitrogen-free anthracene unit with low $\mathrm{H}$ content and high $\mathrm{C}$ content in CSA. Chitosan 
contains amino groups which can form Schiff base compounds with aldehyde substances under certain conditions. The reaction was generally carried out in ethanol solution, and the generated products were insoluble in ethanol. After the end of the reaction, the products were obtained by washing with ethanol for several times. Because of chitosan as a polymer, it can be treated as a mixture with different degree of polymerization. When it reacted with the aldehyde material, some chitosan molecules might have multiple amino groups participated in the reaction with aldehyde, some chitosan might not involved in the reaction. Considering that chitosan and the product were not soluble in ethanol, the unreacted chitosan as a product may mix in the final product. To confirm the composition of the product, the following calculations were used to calculate the mass ratio of chitosan and the amount of aldehydes involved in the reaction in this product.

In the Schiff base condensation reaction of chitosan with a substance containing aldehyde group, the chemical reaction of an amino group with an aldehyde group can be expressed as follow:

$$
\mathrm{R}_{1}-\mathrm{NH}_{2}+\mathrm{R}_{2}-\mathrm{CHO} \longrightarrow \mathrm{R}_{1}-\mathrm{N}=\mathrm{CH}-\mathrm{R}_{2}+\mathrm{H}_{2} \mathrm{O}
$$

The masses of 9-anthralaldehyde reacting with chitosan and chitosan added in the reaction system were set as $m_{1}$ and $m_{2}$, respectively. The molar mass of 9-anthralaldehyde was $M_{2}$, then the mole number of $\mathrm{R}_{2}-\mathrm{CHO}$ was $\mathrm{m}_{2} / \mathrm{M}_{2}$, the total mass $(\mathrm{m})$ of the product can be theoretically calculated according to the equation (1).

$$
\mathrm{m}=m_{1}+m_{2}-1 \times \frac{m_{2}}{M_{2}} \times 18
$$

Where, $m_{1}$ and $m_{2}$ can be obtained from the following equations,

$$
\begin{aligned}
& C \%=\frac{\mathrm{m}_{1} C_{1} \%+\mathrm{m}_{2} \times C_{2} \%}{m} \times 100 \% \\
& H \%=\frac{\mathrm{m}_{1} \times H_{1} \%+\mathrm{m}_{2} \times H_{2} \%-2 \times m_{2} / M_{2} \times 1}{m} \times 100 \% \\
& N \%=\frac{\mathrm{m}_{1} \times N_{1} \%}{m}
\end{aligned}
$$

Where $\mathrm{C} \%$ and $\mathrm{H} \%$ represent the percentage of $\mathrm{C}$ and $\mathrm{H}$ in the product, respectively, which can be obtained directly by measuring the element content of the product; $\mathrm{C}_{1} \%, \mathrm{H}_{1} \%$ and $\mathrm{N}_{1} \%$ were the percentages of $\mathrm{C}, \mathrm{H}$ and $\mathrm{N}$ in chitosan, which can be obtained directly by measuring the element content of chitosan. Among them, $\mathrm{C}_{2} \%$ and $\mathrm{H}_{2} \%$ were the percentage content of $\mathrm{C}$ and $\mathrm{H}$ in 9-anthralaldehyde molecules, which can be directly calculated by the molecular formula of the aldehyde. 
By solving equation (1-4), the mass ratio of chitosan $\left(m_{1}\right)$ and the mass of 9-anthralaldehyde $\left(m_{2}\right)$ involved in the reaction can be quantitatively determined, the calculation value was 1.0536 , which was obtained as the followings: since the carbon content was the highest in the sample, the relative measurement error of carbon was relatively smaller than that of $\mathrm{H}$ and $\mathrm{N}$ in the sample. Therefore, the carbon content obtained by the elemental analysis and the theoretically inferred product quality calculation formula were selected to calculate the mass ratio $\left(\mathrm{m}_{1} / \mathrm{m}_{2}\right)$. The theoretical values of $\mathrm{H}$ and $\mathrm{N}$ were calculated by substituting them into the theoretical content calculation formulas of hydrogen and nitrogen, and the theoretical values were compared with the actual measured percentage contents of $\mathrm{H}$ and $\mathrm{N}$. The results showed that the calculated theoretical value was basically consistent with the actual measured value, indicating that the calculated ratio of $m_{1}$ to $m_{2}$ was correct. Therefore, the mass ratio of chitosan to 9-anthraldehyde involved in the reaction was obtained. The elemental analysis data of chitosan and CSA and the calculated values for CSA were listed in Table S1.

\subsection{Thermal stability}

In order to understand the thermal decomposition behavior of CSA and CSA/DOPO modified epoxy resins, CSA, EP, EP/8\%CSA, EP/8\%DOPO and EP/2.66\%CSA/5.34\%DOPO were studied by thermogravimetric analyzer. Fig. 3 showed the TGA and DTG curves of all the samples, the corresponding results were listed in Table S2. As seen from Fig. 3 that CSA has the highest residual char $34.6 \%$ at $750^{\circ} \mathrm{C}$ and lowest weight-loss rate at maximum weight loss temperature $\left(T_{\max }\right)$, indicating that CSA has excellent char-forming properties. However, the initial decomposition temperature $T_{5 \%}$ and $T_{\text {max }}$ of CSA were the lowest ones among the tested samples, revealing that CSA has lower thermal stability than other EP composites. It was found that EP/8\%CSA exhibited the highest $\mathrm{T}_{\max }$ and char residue among the EP composites, revealing that the introduction of CSA improved the thermal stability and char-forming property of EP. In addition, the char residue of EP/8\%DOPO was only $12.6 \%$ at $750^{\circ} \mathrm{C}$, which was the lowest one in the tested samples. So, it can be concluded that the introduction of DOPO into EP greatly decreased the char-forming properties of EP. For EP/2.66\%CSA/5.34\%DOPO, it was observed that the residue char amount was increased $28.8 \%$ relative to $\mathrm{EP} / 8 \% \mathrm{DOPO}$, reduced $12.7 \%$ relative to $\mathrm{EP} / 8 \% \mathrm{CSA}$, exhibiting a comparable char-forming property with EP.

\subsection{Flame retardancy performance}

The LOI value and UL-94 test were adopted as the frequently-used methods for evaluating the flame retardancy of materials. The test results were summarized in Table 1. As shown in Table 1 that the LOI value of the EP sample was $22.6 \%$, which was the lowest one in all the samples. Except the EP has the dripping phenomenon, all the other samples containing CSA, DOPO or CSA and DOPO in EP has no dripping in the combustion process. The LOI value of the EP/1.66\%CSA/3.34\%DOPO was $34.5 \%$, which was increased by $52.6 \%$ compared with the EP sample. When the total content of CSA/DOPO was increased to $8 \mathrm{wt} \%$ with the mass ratio of CSA to DOPO was 1:2, the LOI value of $\mathrm{EP} / 2.66 \% \mathrm{CSA} / 5.34 \% \mathrm{DOPO}$ samples was $36.4 \%$, which was an increase of $61.1 \%, 31.9 \%$ and $6.4 \%$ relative to the $\mathrm{EP}, \mathrm{EP} / 8 \% \mathrm{CSA}$ and $\mathrm{EP} / 8 \% \mathrm{DOPO}$ samples, respectively. The results show that the 
synthesized flame retardant synergist CSA had a good synergistic effect with DOPO on the flame retardant properties of EP composites. In the UL-94 test, the EP samples were completely burned out and obtained no rating. EP/2.66\%CSA/5.34\%DOPO and EP/2.01\%CSA/5.99\%DOPO can pass the $\mathrm{V}-0$ rating, while, EP/8\%DOPO only reached V-1 rating and EP/8\%CSA exhibited no rating. It indicated that the synergistic function of CSA and DOPO was contributed to the improvement of the flame retardant properties of EP.

Table 1 Composition of epoxy mixtures and the results of LOI tests and UL-94

\begin{tabular}{|c|c|c|c|c|c|}
\hline \multirow[t]{2}{*}{ Samples } & \multicolumn{3}{|c|}{ EP DDM CSA DOPO LOI } & \multicolumn{2}{|c|}{ UL-94 } \\
\hline & (g) $\quad(g) \quad(g)$ & (g) & (\%) & Dripping & Rating \\
\hline EP & $25.006 .50 \quad 0$ & 0 & $\overline{22.6}$ & $\mathrm{Y}$ & No Rating \\
\hline $\mathrm{EP} / 5 \% \mathrm{CSA}$ & 25.006 .501 .66 & 0 & 25.7 & $\mathrm{~N}$ & No Rating \\
\hline $\mathrm{EP} / 5 \% \mathrm{DOPO}$ & $25.006 .50 \quad 0$ & 1.66 & 32.3 & $\mathrm{~N}$ & $\mathrm{~V}-1$ \\
\hline $\mathrm{EP} / 2.5 \% \mathrm{CSA} / 2.5 \% \mathrm{DOPO}$ & 25.006 .500 .83 & 0.83 & 32.6 & $\mathrm{~N}$ & $\mathrm{~V}-1$ \\
\hline $\mathrm{EP} / 1.66 \% \mathrm{CSA} / 3.35 \% \mathrm{DOPO}$ & 25.006 .500 .55 & 1.11 & 34.5 & $\mathrm{~N}$ & $\mathrm{~V}-1$ \\
\hline $\mathrm{EP} / 1.27 \% \mathrm{CSA} / 3.74 \% \mathrm{DOPO}$ & 25.006 .500 .42 & 1.24 & 35.6 & $\mathrm{~N}$ & $\mathrm{~V}-1$ \\
\hline $\mathrm{EP} / 8 \% \mathrm{CSA}$ & 25.006 .502 .74 & 0 & 27.6 & $\mathrm{~N}$ & No Rating \\
\hline $\mathrm{EP} / 8 \% \mathrm{DOPO}$ & $25.006 .50 \quad 0$ & 2.74 & 34.2 & $\mathrm{~N}$ & V-1 \\
\hline $\mathrm{EP} / 4 \% \mathrm{CSA} / 4 \% \mathrm{DOPO}$ & 25.006 .501 .37 & 1.37 & 36.3 & $\mathrm{~N}$ & $\mathrm{~V}-1$ \\
\hline $\mathrm{EP} / 2.66 \% \mathrm{CSA} / 5.34 \% \mathrm{DOPO}$ & 25.006 .500 .91 & 1.83 & 36.4 & $\mathrm{~N}$ & $\mathrm{~V}-0$ \\
\hline $\mathrm{EP} / 2.01 \% \mathrm{CSA} / 5.99 \% \mathrm{DOPO}$ & 25.006 .500 .69 & 2.05 & 37.5 & $\mathrm{~N}$ & $\mathrm{~V}-0$ \\
\hline
\end{tabular}

In addition, the combustion behavior of EP materials was tested with a cone calorimeter (CC).

Fig. 4 showed the heat release rate (HRR), total heat release rate (THR), smoke generation rate (SPR) and total smoke generation (TSP) curves of EP and EP/2.66\%CSA/5.34\%DOPO samples. The CC test results were listed in Table 2. It showed that the TTI value of EP/2.66\%CSA/5.34\%DOPO samples increased from $59 \mathrm{~s}$ in EP to $82 \mathrm{~s}$. The improvement of the ignition resistance of the matrix was attributed to the release of volatile products produced by the early decomposition of CSA/DOPO, which could capture or dilute oxygen. Relative to EP, EP/2.66\%CSA/5.34\%DOPO had much higher residual char amount, which increased by $151 \%$, and very lower peak heat release rate (PHRR), which decreased by $36.0 \%$.

In TGA test, the residue char of EP/2.66\%CSA/5.34\%DOPO was slightly lower than that of EP in $\mathrm{N}_{2}$ atmosphere, while, in $\mathrm{CC}$ test, the obvious increase of the residue char amount of 
$\mathrm{EP} / 2.66 \% \mathrm{CSA} / 5.34 \% \mathrm{DOPO}$ can be attributed to the existence of oxygen, which was the only difference in the two kinds of tests. It indicated that oxygen can improve the formation of more residue char of $\mathrm{EP} / 2.66 \% \mathrm{CSA} / 5.34 \% \mathrm{DOPO}$, which was beneficial to resist fire. FIGRA was defined as the maximum value of $H R R / t_{p}$, which was equal to PHRR/ $t_{p}$ in accordance with general practice. FIGRA was an important parameter for evaluating fire risk (Schartel et al. 2007). It can be seen from Table 2 that the FIGRA value of EP/2.66\%CSA/5.34\%DOPO was about $40 \%$ lower than that of EP sample, indicating a significant function in reducing the fire risk. More importantly, it was worth noting that the peak smoke production rate (PSPR) and total smoke release (TSP) values of EP/CSA2.66\%/5.34\%DOPO were much lower than those of the EP sample, illustrating that the combination of CSA2.66\% and $5.34 \% \mathrm{DOPO}$ can significantly improve the smoke suppression effect of EP. The superior behavior of EP/2.66\%CSA/5.34\%DOPO both in smoke suppression and flame retardancy can be ascribed to the following reasons: 1 ) the lower thermal stability of CSA promotes the earlier escape of some non-flammable gases such as $\mathrm{NH}_{3}$ and $\mathrm{CO}_{2}$, diluting combustible gases, 2) P containing radicals derived from the DOPO units in EP/2.66\%CSA/5.34\%DOPO help to capture the radicals of chain reactions (Schartel et al. 2008), 3) the rich and dense char layer also plays a role of isolation and quenching heat transfer.

Table 2 The CC test results of EP and EP/2.66\%CSA/5.34\%DOPO

\begin{tabular}{|c|c|c|}
\hline Sample & $\mathrm{EP}$ & $\mathrm{EP} / 2.66 \% \mathrm{CSA} / 5.34 \% \mathrm{DOPO}$ \\
\hline Time for ignitions(s) (TTI) & 59 & 82 \\
\hline Time to peaks $(\mathrm{s})\left(\mathrm{t}_{\mathrm{p}}\right)$ & 130 & 140 \\
\hline Peak heat release rate $\left(\mathrm{KW} \cdot \mathrm{m}^{-2}\right)(\mathrm{PHRR})$ & 1063 & 680.8 \\
\hline Fire growth rate index (FIGRA) & 8.17 & 4.9 \\
\hline Total heat release $\left(\mathrm{MJ} \cdot \mathrm{m}^{-2}\right)(\mathrm{THR})$ & 97.6 & 83.7 \\
\hline Peak smoke produce rate $\left(\mathrm{m}^{2} \cdot \mathrm{s}^{-1}\right)$ (PSPR) & 0.54 & 0.29 \\
\hline Total smoke release $\left(\mathrm{m}^{2}\right)(\mathrm{TSP})$ & 71.4 & 27.2 \\
\hline $\begin{array}{l}\text { Maximum average heat release rate (MARHE) } \\
\left(\mathrm{KW} \cdot \mathrm{m}^{-2}\right)\end{array}$ & 301.8 & 258.7 \\
\hline Average CO yield $\left(\mathrm{kg} \cdot \mathrm{kg}^{-1}\right)(\mathrm{AV}-\mathrm{COY})$ & 0.054 & 0.14 \\
\hline Average $\mathrm{CO}_{2}$ yield $\left(\mathrm{kg}^{\mathrm{kg}} \mathrm{kg}^{-1}\right)\left(\mathrm{AV}-\mathrm{CO}_{2} \mathrm{Y}\right)$ & 0.995 & 2.6 \\
\hline Char residue (\%) & 11.9 & 29.9 \\
\hline
\end{tabular}

\subsection{Analysis of char residue}


Fig. 5 showed the macrostructure and microstructure of the char residues left behind after the CC test. Fig. 5a showed that the residual carbon left behind after EP combustion exhibited incontinuous fiber-like structure with large pores and low in quality. The char residue in this form cannot isolate the exchange of the produced combustion gases and cannot protect the substrate from burning. With the increase of the amount of CSA and DOPO in EP, it was found that the char residue became more denser with higher combustion char residue. It indicated that the addition of CSA/DOPO can increase the mass and compactness of residual char, playing a role in condensed phase flame retardant effect.

The residual carbon after CC test was systematically studied by elemental analysis, infrared spectroscopy and Raman spectroscopy. In Fig. 6, two significant peaks at $1594 \mathrm{~cm}^{-1}$ and $1374 \mathrm{~cm}^{-1} \mathrm{can}^{2}$ be assigned to the $G$ band and the $D$ band, respectively. In general, $G$ band is attributed to $\mathrm{sp}^{2}$ hybridized carbon atom, and $\mathrm{D}$ band belongs to amorphous carbon (Mauere et al. 2005). Therefore, the graphitization degree of the material can be reflected by the integral intensity ratio $\left(\mathrm{I}_{D} / \mathrm{I}_{G}\right)$ of the $D$ and $G$ band. With the decrease of the proportion, the graphitization degree increases, leading to better flame retardant performance (Sadezky et al. 2005). Fig. 6 shows that the $I_{D} / I_{G}$ value (3.93) of EP was greater than that of EP/CSA2.66\%/5.34\%DOPO sample (3.52), indicating that the char layer formed by the combustion of EP/CSA2.66\%/5.34\%DOPO has a higher degree of graphitization than that of the char residue of EP, which was beneficial to better prevent heat transfer in the combustion process.

Fig. S1 showed the FTIR spectra of the char residues from EP/2.66\%CSA/5.34\%DOPO and EP. The two curves exhibited similar main absorption peaks at $2921 \mathrm{~cm}^{-1}$ and $1619 \mathrm{~cm}^{-1}$, corresponding to the vibration of the aromatic ring. The signal peaks at $1080 \mathrm{~cm}^{-1}$ and $3422 \mathrm{~cm}^{-1}$ belonged to $\mathrm{C}-\mathrm{O}$ and $\mathrm{O}-\mathrm{H}$ bonds, respectively. There were three new absorption peaks at $1159 \mathrm{~cm}^{-1}, 1236 \mathrm{~cm}^{-1}$ and $1509 \mathrm{~cm}^{-1}$ in the char residues of $\mathrm{EP} / 2.66 \% \mathrm{CSA} / 5.34 \% \mathrm{DOPO}$, which were assigned to the stretching vibrations of P-O-C, $\mathrm{P}=\mathrm{O}$ and $\mathrm{C}-\mathrm{P}$, respectively. The results indicated that some phosphorus compounds existed in the char residue of EP/2.66\%CSA/5.34\%DOPO, which were not found in EP.

The results of elemental analysis of the char residues were listed in Table S3. Compared to EP char residue, the $\mathrm{C}$ content in the char residue of $\mathrm{EP} / 2.66 \% \mathrm{CSA} / 5.34 \% \mathrm{DOPO}$ was increased by $6.25 \%$, and its 0 and $\mathrm{N}$ contents were decreased by $27.9 \%$ and $40.3 \%$, respectively. The $\mathrm{P}$ content of $0.48 \%$ in the char residue of EP/2.66\%CSA/5.34\%DOPO was $37.7 \%$ lower than that in its precursor, which was $0.77 \%$ calculated from the addition mass of DOPO in the sample and $P$ percentage in DOPO. The decrease of $P$ content in the char residue illustrated that some $\mathrm{P}$ containing substances have escaped as gas phase in the combustion, which was proved by the Py-GC/MS analysis of the sample. Generally, the P element in the condensed phase would exist in the form of polyphosphoric acid and its derivatives, promoting the dehydration and carbonization and preventing further combustion.

Additional, XPS was further employed to analyze the composition of the various components of the char residue. Detailed data of $\mathrm{C}_{1 \mathrm{~s}}, \mathrm{~N}_{1 \mathrm{~s}}, \mathrm{O}_{1 \mathrm{~s}}, \mathrm{P}_{2 \mathrm{~s}}$ chemical bonds were listed in Table S4. As shown in Fig. 7, in the $\mathrm{C}_{1 \mathrm{~s}}$ spectrum, the peaks at $284.4 \mathrm{eV}$ was assigned to $\mathrm{C}-\mathrm{H}$ and $\mathrm{C}-\mathrm{C}$ bonds in the aliphatic and aromatic 
components, and the peaks of $\mathrm{C}-\mathrm{N}$ bond and $\mathrm{C}-\mathrm{OH}$ bond were observed at $285.4 \mathrm{eV}$, and $\mathrm{C}-\mathrm{C}$ and $\mathrm{C}-\mathrm{O}$ bonds were observed at $288.7 \mathrm{eV}$. Compared with EP, the peak at $288.7 \mathrm{eV}$ decreased (partially migrated to $290.2 \mathrm{eV}$ ), and the peak at $284.4 \mathrm{eV}$ increased for the EP/2.66\% CS/5.34\%DOPO, showing that the compound of CSA and DOPO could reduce the generation of oxidized substances during the combustion of EP materials (Levchik et al. 2005). In the $\mathrm{N}_{1 \mathrm{~s}}$ spectrum, the peaks at $398.6 \mathrm{eV}$ and $400.2 \mathrm{eV}$ were assigned to the $\mathrm{C}-\mathrm{N}$ and $\mathrm{C}=\mathrm{N}$ bond, severally. In the $\mathrm{O}_{1 \mathrm{~s}}$ spectrum of $\mathrm{EP}$, the peak at $533.2 \mathrm{eV}$ attributed to $\mathrm{C}-\mathrm{OH}$ and $\mathrm{C}-\mathrm{O}-\mathrm{C}$ groups, while peak at $532.2 \mathrm{eV}$ was assigned to $\mathrm{C}=0$. For the $\mathrm{EP} / 2.66 \% / 5.34 \% \mathrm{DOPO}$, the peaks at 532.2 and $533.2 \mathrm{eV}$ were also observed, however, the peaks were wider than those of EP, which related to the formation of P-O-C group in the char residue of EP/2.66\%/5.34\%DOPO. In the $\mathrm{P}_{2 \mathrm{~s}}$ spectrum, the peak at $133.4 \mathrm{eV}$ was attributed to $\mathrm{P}=\mathrm{O}$, and the peak at $134.2 \mathrm{eV}$ can be attributed to $\mathrm{P}-\mathrm{OH}$ and $\mathrm{P}-\mathrm{O}-\mathrm{C}$ bond, indicating that $\mathrm{P}$ containing substances were generated during the formation of residual carbon, while no P-containing peak shown in the char residue of EP.

According to reports in the literature, DOPO undergoes thermal decomposition during the combustion process to release free radicals containing $\mathrm{P}$, thereby playing a flame retardant effect in the gas phase ( $\mathrm{Li}$ et al. 2020; Tang and Zhou 2019). Py-GC/MS was carried out for the EP sample and $\mathrm{EP} / 2.66 \% \mathrm{CSA} / 5.34 \% \mathrm{DOPO}$ respectively, to dissect the gas flame-retardant mechanism at 500 ${ }^{\circ} \mathrm{C}$. Fig. S2 exhibited the pyrolysis diagram of EP, and the main cracked products were listed in Table S5. As shown in Table S5, the pyrolysis products of EP samples were mainly derivatives of DDM and epoxy resin. Among them, thermal cracking produces $\cdot \mathrm{OH}$ radicals and $\cdot \mathrm{H}$ radicals were the main reasons for the inflammability of thermosetting epoxy resins.

The pyrolysis spectrum of EP/2.66\%CSA/5.34\%DOPO was shown in Fig. 8. The identified specific products were listed in Table 3. Some characteristic products of the flame retardant pyrolysis of $\mathrm{EP} / 2.66 \% \mathrm{CSA} / 5.34 \% \mathrm{DOPO}$ were as follows: methylaminoacetic acid (peak 1), L-alanylglycine (peak 2), paromomycin (peak 3), 4-hydroxy Phenyl phosphate (peak 4), o-cresol (peak 5), 2-isopropylphenol (peak 6), o-phenylphenol (peak 7), dibenzofuran (peak 8), fluorene (peak 9) and 9-hydroxy-4-methoxyacridine (peak 10). The existence of these substances can be explained by the structure of CSA/DOPO flame retardant. The pyrolysis products 4, 7-9 can be attributed to the decomposition of DOPO, accompanying with the production of $\mathrm{PO}$ and $\mathrm{PO}_{2}$ radicals. These phosphorus-containing radicals can trap active free radicals during the combustion process and terminate radical chain reactions (Jellinek et al. 1977). Peak 1-3 were mainly corresponding to the cracking of chitosan fragments in CSA. The peaks located in the retention time more than 22.0 mins in the pyrolysis spectrum of EP/2.66\%CSA/5.34\%DOPO were also found in that of EP, indicating that these substances related to these peaks come from the similar components with EP. The amino groups containing compounds can generate non-combustible gases, such as $\mathrm{CO}_{2}, \mathrm{H}_{2} \mathrm{O}$ and $\mathrm{NH}_{3}$, diluting the combustion gases and reducing the heat release.

On the basis of the above analysis, the flame retardant mechanism of EP/2.66\%CSA/5.34\%DOPO can be summarized as follows: with the increase of temperature, the gradual decomposition of DOPO and CSA promoted the release of $\mathrm{PO}$. radicals and non-combustible gases such as $\mathrm{CO}_{2}, \mathrm{H}_{2} \mathrm{O}$ and $\mathrm{NH}_{3}$, thus 
quenching in the gas phase. In the condensed phase, the polyhydroxyl and aromatic rings in CSA and the phosphorus-containing compounds generated by DOPO decomposition can accelerate the formation of a more uniform and dense coke layer, so as to realize the thermal oxygen barrier effect.

Table 3 Some characteristic products identified in the pyrolytic diagram of $\mathrm{EP} / 2.66 \% \mathrm{CSA} / 5.34 \% \mathrm{DOPO}$

\begin{tabular}{|c|c|c|c|}
\hline Peaks & Times & $\mathrm{m} / \mathrm{z}$ & Chemical structure \\
\hline 1 & 1.07 & 89 & \\
\hline 2 & 2.22 & 160 & \\
\hline 3 & 2.92 & 615 & \\
\hline 4 & 9.35 & 174 & \\
\hline 5 & 10.07 & 108 & \\
\hline 6 & 12.32 & 136 & \\
\hline 7 & 16.33 & 170 & \\
\hline 8 & 16.46 & 168 & \\
\hline 9 & 17.21 & 166 & \\
\hline 10 & 21.03 & 225 & \\
\hline
\end{tabular}




\subsection{TG-FTIR analysis of EP and EP/2.66\%CSA/5.34\%DOPO samples}

TGA-FTIR spectra was used to obtain a further disclose of the flame-retardant behavior of the EP/266\%CSA/5.34\%DOPO. The FTIR spectra of the pyrolysis gas products of EP and $\mathrm{EP} / 2.66 \% \mathrm{CSA} / 5.34 \% \mathrm{DOPO}$ samples at $300,350,400,450,500,550$ and $600{ }^{\circ} \mathrm{C}$ from TGA were shown in Fig. 9. As shown in Fig. 9 (a, b), EP samples exhibited the characteristic absorption peaks of some thermally cracked molecules, such as hydrocarbons $\left(2970 \mathrm{~cm}^{-1}, 1180 \mathrm{~cm}^{-1}\right), \mathrm{CO}_{2}\left(2360 \mathrm{~cm}^{-1}\right), \mathrm{C}=0$ $\left(1740 \mathrm{~cm}^{-1}\right)$ and Ph-O-C (1260 $\left.\mathrm{cm}^{-1}\right)$ (Kong et al. 2019; Wu et al. 2009; Sergei et al. 2004), respectively. The peaks at 4000-3500 $\mathrm{cm}^{-1}$ and $1300-1600 \mathrm{~cm}^{-1}$ were ascribed to water (Wu et al. 2009; Sergei et al. 2004; Liu et al. 2018). These small molecule compounds were mainly attributed to the thermal cracking of EP.

Particularly, as shown in Fig. 9 (c, d), the peak at $1130 \mathrm{~cm}^{-1}$ in the FTIR spectra of the gaseous products of EP/2.66\%CSA/5.34\%DOPO was attributed to the Ph-P bond (Li et al. 2018). What's more, the peak at $1260 \mathrm{~cm}^{-1}$ was assigned to Ph-O-C, which was probably overlapped with the characteristic absorbance of ether bonds (Li et al. 2018; Wang et al. 2010; Qian et al. 2011). It can be seen that there were phosphoruscontaining fragments in the pyrolysis gas of EP/2.66\%CSA/5.34\%DOPO samples, indicating that the CSA/DOPO flame retardancy system plays an active role in the gas phase, which was consistent with the conclusion of Py-GCMS.

In order to further understand the changes of pyrolysis products, Fig S3 shows the changes in the absorbance of EP and EP/2.66\%CSA/5.34\%DOPO pyrolysis products over time (a) and the curve obtained from the first derivative (b). As can be seen from the figure that the pyrolysis products of $\mathrm{EP} / 2.66 \% \mathrm{CSA} / 5.34 \% \mathrm{DOPO}$ begin to be released about $30.2 \mathrm{~min}$, while the pyrolysis products of EP begin to release around $31.4 \mathrm{~min}$. Additionally, it can be observed from Fig. 9 (c, d) that the thermal cracking of $\mathrm{EP} / 2.66 \% \mathrm{CSA} / 5.34 \% \mathrm{DOPO}$ produces $\mathrm{CO}_{2}$ not only earlier, but also the absorption peak was more obvious, indicating that CSA/DOPO began to decompose at the early stage of thermal degradation of $\mathrm{EP} / 2.66 \% \mathrm{CSA} / 5.34 \% \mathrm{DOPO}$.

\subsection{Mechanical properties}

In order to study the effect of CSA/DOPO flame retardant on the mechanical properties of epoxy resin materials. The measurements of unnotched impact strength, tensile strength and flexural strength were conducted on EP, EP/8\%DOPO and EP/2.66\%CSA/5.34\%DOPO. The results were presented in Table 4. It was observed that the mechanical properties increased according to the order of EP, EP/8\%DOPO and $\mathrm{EP} / 2.66 \% \mathrm{CSA} / 5.34 \% \mathrm{DOPO}$. The increase of the flexural strength of EP/2.66\%CSA/5.34\%DOPO was most obvious, which increased by $52.3 \%$. The improved mechanical properties of the modified EP can be attributed to the reaction activity of CSA and DOPO with the epoxy groups in EP in the curing procedure. The - $\mathrm{OH}$ and $\mathrm{NH}_{2}$ in CSA and - $\mathrm{P}-\mathrm{H}$ groups in DOPO can participate in the ring opening reaction of epoxy groups in EP at high temperature, which were shown in Scheme 1, The formed strong interactions greatly improved the compatability of CSA and DOPO with EP. Moreover, the hydrogen bond interactions among 
the polar groups such as $-\mathrm{OH}$ and $-\mathrm{NH}$ - in the modified EP were also beneficial to increase its mechanical strength. (see Scheme 1 in the Supplementary Files)

To the best of our knowledge, EP/2.66\%CSA/5.34\%DOPO was the first report for the CS-containing flame retardants, which simultaneously improve both the flame retardancy and mechanical properties of EP. For comparison, the relative data of flame retardancy and mechanical properties for the CS-containing flame retardants in EP was listed in Table S6. Compared with CCD modified EP composite (EP/10\%CCD) (Chen et al. 2020), EP/2.66\%CSA/5.34\%DOPO exhibits comparable flame retardancy with higher LOI value and enhanced mechanical properties. It was worth mentioning that the preparation of the flame retardant in $\mathrm{EP} / 2.66 \% \mathrm{CSA} / 5.34 \% \mathrm{DOPO}$ was much easier than that of EP10\%CCD. CSA was synthesized by Shiff base condensation, which was similar with the first step for the synthesis of CCD. However, the Shiff base compound needed to further react with DOPO to produce CCD, while, the flame retardant in $\mathrm{EP} / 2.66 \% \mathrm{CSA} / 5.34 \% \mathrm{DOPO}$ was the combined action of CSA and DOPO, which was prepared by simple mixing of CSA and DOPO.

Table 4 Mechanical properties of EP, EP / 8\%DOPO and EP/2.66\%CSA/5.34\%DOPO

\begin{tabular}{|llll|}
\hline Sample & $\begin{array}{l}\text { Tensile strength } \\
(\mathrm{MPa})\end{array}$ & $\begin{array}{l}\text { Flexural strength } \\
(\mathrm{MPa})\end{array}$ & $\begin{array}{l}\text { Izod impact strength } \\
\left(\mathrm{KJ} \cdot \mathrm{m}^{-2}\right)\end{array}$ \\
\hline $\mathrm{EP}$ & $54 \pm 4$ & $86 \pm 3$ & $21 \pm 1$ \\
\hline $\mathrm{EP} / 8 \% \mathrm{DOPO}$ & $58 \pm 3$ & $97 \pm 2$ & $22 \pm 2$ \\
\hline EP/2.66\%CSA/5.34\%DOPO & $63 \pm 3$ & $131 \pm 2$ & $28 \pm 2$ \\
\hline
\end{tabular}

\section{Conclusions}

In this work, a flame retardant synergist (CSA) was successfully synthesized, and the EP/CSA/DOPO thermosetting material obtained by compounding DOPO and CSA with EP had good flame retardant properties. Based on the UL-94 test, EP/2.66\%CSA/5.34\%DOPO passed a V-0 rating and had the LOI value of $36.4 \%$, an increase of $61.06 \%$ compared with $22.6 \%$ for EP. In comparison with the EP,

$\mathrm{EP} / 2.66 \% \mathrm{CSA} / 5.34 \% \mathrm{DOPO}$ composites exhibits the following merits, 1 ) the PHRR, PSPR and TSP values were significantly reduced, 2) the mechanical properties have been much improved, which are contributed to the reaction activity of the functional groups in CSA and DOPO with the epoxy groups in EP in the curing procedure, 3 ) the char residue amount increased by $151 \%$. The analyses of TG-FTIR, CC tests and Py-GC/MS of EP composites further supported the synergistic significance of CSA and DOPO on flame retardant properties, which can release PO radicals and non-combustible gases such as $\mathrm{CO}_{2}$, $\mathrm{H}_{2} \mathrm{O}$ and $\mathrm{NH}_{3}$ in the gas phase and form a more uniform and dense coke layer to realize the thermal oxygen barrier effect. It can also be concluded that simple mixing of several substances with respective function according to a certain mass ratio can greatly improve the relative properties of the synthesized composites. 


\section{Declarations}

Funding: This study was funded by Hubei provincial science and technology department (2018ACA158).

Conflicts of interests: All authors certify that they have no affiliations with or involvement in any organization or entity with any financial interest or non-financial interest in the subject matter or materials discussed in this manuscript.

Availability of data and material: All data generated or analyzed during this study were included in this published article (and its supplementary information files).

Code availability: No software application or custom code.

Authors' contributions: Junjie Wang, synthesis, writing and analysis; Xuejun Yu, characterization; Shengsong Dai, analysis; Xinyu Wang, analysis; Zhiquan Pan, analysis; Hong Zhou, Design and revise of the work.

\section{References}

Bifulco A, Parida D, Salmeia KA, Nazir R, Gaan S (2020) Fire and mechanical properties of DGEBA-based epoxy resin cured with a cycloaliphatic hardener: Combined action of silica, melamine and DOPOderivative. Materials \& design 65: 108862-108871. https://doi. org/ $\quad$ 10.1016/j.matdes.2020.108862

Bin Y, Weiyi X, Wenwen G, Shuilai Q, Xin W, Siuming L, Yuan H (2016) Thermal exfoliation of hexagonal boron nitride for effective enhancements on thermal stability, flame retardancy and smoke suppression of epoxy resin nanocomposites via sol-gel process. Journal of Materials Chemistry A 4: 73307340. https://doi.org/10.1039/C6TA01565D

Dash, M, Chiellini F, Ottenbrite RM, Chiellini E (2011) Chitosan-A versatile semi-synthetic polymer in biomedical applications. Progress in Polymer Science 36(8): 981-1014. https://doi.org/10.1016/j. progpolymsci.2011.02.001

Dongxue Y, Lingfeng L, Binling C, Shuxian S, Jun N, Guiping M (2019) Functionalized chitosan electrospun nanofifiber membranes for heavy-metal removal. Polymer 163: 74-85. https://doi. org/10.1016/j.polymer.2018.12.046

Hao T, ZongMin Z, Rui C, JunJie W, Hong Z (2019) Synthesis of DOPO-based pyrazine derivative and its effect on flame retardancy and thermal stability of epoxy resin. Polym Adv Technol 30: 23312339. https://doi.org/10.1002/pat.4674

Hao T, Hong Z (2019) A novel nitrogen, phosphorus, and boron ionic pair compound toward fire safety and mechanical enhancement effect for epoxy resin. Polymers for Advanced Technologies 31: 1-

13. https://doi.org/10.1002/pat.4823 
Haihua Y, Xiuhang X, Yunfei X, Mingzhen P, Nighat Z, Bo P, Anis UR, Min W, Henmei N (2020) Synthesis of a novel modified chitosan as an intumescent flame retardant for epoxy resin. e-Polymers 20: 303316. https://doi.org/10.1515/epoly-2020-0036

Haihua Y, Yunfei X, Xiuhang X, Nighat Z, Min W, Henmei N (2020) Preparation of organic-inorganic intumescent flame retardant with phosphorus, nitrogen and silicon and its flame retardant effect for epoxy resin. Journal of Applied Polymer Science 137: 49256-49268. https://doi. org/10.1002/app.49256

Ionela DC, Diana S, Tachita VB, Corneliu H, Adina C, Gabriela L, Celia GL, Mónica FS, Vicente FP, Maria DRS (2014) A straightforward, eco-friendly and cost-effective approach towards flame retardant epoxy resins. Journal of Materials Chemistry A 2: 16230-16241. https://doi.org /10.1039/c4ta03197k

Jellinek H, Takada K (1977) Toxic gas evolution from polymers: Evolution of hydrogen cyanide from polyurethanes. Journal of Polymer Science: Polymer Chemistry Edition 15: 2269-

2288. https://doi.org/10.1002/pol.1977.170150917

Kun W, Lei S, Yuan H, Hongdian L, Baljinder KK, Everson K (2009) Synthesis and characterization of a functional polyhedral oligomeric silsesquioxane and its flame retardancy in epoxy resin. Prog. Org. Coat 65: 490-497. https://doi.org/10.1016/j.porgcoat.2009.04.008

Khalifah A S, Sabyasachi G (2015) An Overview of Some Recent Advances in DOPO derivatives: Chemistry and Flame Retardant Applications. Polymer Degradation and Stability 113: 119134. https://doi.org/10.1016/j.polymdegradstab.2014.12.014

Lijun Q, Longjian Y, Yong Q, Shuren Q (2011) Thermal degradation behavior of the compound containing phosphaphenanthrene and phosphazene groups and its flame retardant mechanism on epoxy resin. Polymer 52(24): 5486-5493. https://doi.org/10.1016/j.polymer.2011.09.053

Levchik S, Piotrowski A, Weil E, Yao Q (2005) New developments in flame retardancy of epoxy resins. Polym Degrad Stab 88: 57-62. https://doi.org/10.1016/j.polymdegradstab.2004.02.019

Lin L, Xiaoming S, Zheng Z, Xiaolin L, Licong J, Kai H, Shuai Z (2020) Synergistic Fire Hazard Effect of a Multifunctional Flame Retardant in Building Insulation Expandable Polystyrene through a Simple Surface-Coating Method. ACS Omega: 5799-5807. https://doi. org/10.1021/acsomega.9b03541

Mauerer 0 (2005) New reactive, halogen-free flame retardant system for epoxy resins. Polymer Degradation and Stability 88: 70-73. https://doi.org/10.1016/j.polymdegradstab.2004.01.027

Mengmeng Z, Wenjing Z, Xia Z, Zhiwei L, Laigui Y, Xiaohong, Zhijun Z (2021) Nonfuoride-modifed halloysite nanotube-based hybrid: potential for acquiring super-hydrophobicity and improving fame retardancy of epoxy resin. Journal of Nanostructure in Chemistry 1950154:1-15. https://doi.org/10.1007/s40097-020-00371-9 
Mengmeng Z, Yamin C, Zhiwei L, Xiaohong L, Laigui Y, Zhijun Z (2019) Biomass Chitosan-Induced $\mathrm{Fe}_{3} \mathrm{O}_{4}$ Functionalized Halloysite Nanotube Composites: Preparation, Characterization and Flame-Retardant Performance. NANO 14: 1950154-1950169. https://doi.org/10.1142/S1793 292019501546

Prabhakar MN, Song JI (2020) Influence of chitosan-centered additives on flammable properties of vinyl ester matrix composites. Cellulose 27(4): 8087-8103. https://doi.org/10.1007/ s10570-020-03313-4

Pooja D, Sonu G, Ajai KS (2018) Base free N-alkylation of anilines with $\mathrm{ArCH}_{2} \mathrm{OH}$ and transfer hydrogenation of aldehydes/ketones catalyzed by the complexes of $\eta^{5}-\mathrm{Cp} * \operatorname{lr}(\mathrm{III})$ with chalcogenated Schiff bases of anthracene-9-carbaldehyde. DaltonTrans 47: 3764-

3774. https://doi.org/10.1039/C7DT04326K

Qinghong K, Yi Z, Xin Z, Bing X, Yanzhu Y, Junyu Z, Feng Z, Jia Z, Junhao Z (2019) Functionalized Montmorillonite Intercalation Iron Compounds for Improving Flame Retardancy of Epoxy Resin Nanocomposites. Journal of Nanoscience and Nanotechnology 19: 5803-5809. https://doi.org/ 10.1166/jnn.2019.16540

Rui C, Zijin L, XueJun Y, Hao T, Yuan Z, Hong Z (2020) Synthesis of chitosan-based flame retardant and its fire resistance in epoxy resin. Carbohydrate Polymers 245: 116530-

116537. https://doi.org/10.1016/j.carbpol.2020.116530

Schartel B, Braun U, Balabanovich Al, Artner J, Ciesielski M, Döring M, Perez RM, Sandler JKW, Altstädt V (2008) Pyrolysis and fire behaviour of epoxy systems containing a novel 9,10-dihydro-9-oxa-10phosphaphenanthrene-10-oxide-(DOPO)-based diamino hardener. European Polymer Journal 44: 704715. https://doi.org/10.1016/j.eurpolymj.2008.01.017

Sergei VL, Edward DW (2004) Thermal decomposition, combustion and flameretardancy of epoxy resins a review of the recent literature. Polym. Int 53: 1585-1610. https://doi.org/10.1002/pi.1473

Schartel B, Hull TH (2007) Development of fire-retarded materials-Interpretation of cone calorimeter data. Fire Mater 31: 327-354. https://doi.org/10.1002/fam.949

Shuang Y, Jun W, Siqi H, Mei W, Liufeng C (2015) Synthesis of a phosphorus/nitrogen-containing additive with multifunctional groups and its flame-retardant effect in epoxy resin. Industrial \& Engineering Chemistry Research 54: 7777-7786. https://doi.org/10.1021/acs.iecr.5b02026

Shuang H, Lei S, Haifeng P, Yuan H (2012) Thermal Properties and Combustion Behaviors of Chitosan Based Flame Retardant Combining Phosphorus and Nickel. Ind. Eng. Chem. Res 51: 36633669. https://doi.org/10.1021/ie2022527

Shanglin J, Lijun Q, Yong Qiu, Yajun C, Fei X (2019) High-efficiency flame retardant behavior of bi-DOPO compound with hydroxyl group on epoxy resin, Polymer Degradation and Stability 166: 344352. https://doi.org/10.1016/j.polymdegradstab.2019.06.024 
Sadezky A, Muckenhuber H, Grothe H, Niessner R, Pöschl U (2005) Raman microspectroscopy of soot and related carbonaceous materials: Spectral analysis and structural information. Carbon 43:1731-

1742. https://doi.org/10.1016/j.carbon.2005.02.018

Shigehiro H, Min Z, Hideki Y, Yoshiharu K, Kojiro M, Masuo N (2003) Chemical Modification and some Aligned Composites of Chitosan in a Filament State. Macromolecular Bioscience 3: 620628. https://doi.org/10.1002/mabi.200350028

Santosh K, Nidhi N, Ghosh T, Dutta PK, Yadav RS, Pandey AC (2009) Preparation, characterization, and optical properties of a chitosan-anthraldehyde crosslinkable film. Journal of Applied Polymer Science 115: 3056-3062. https://doi.org/10.1002/app.31385

Tentu NR, Imad H, Ji EL, Akshay K, Bon HK (2019) Enhanced Thermal Properties of Zirconia Nanoparticles and Chitosan-Based Intumescent Flame Retardant Coatings. Applied Sciences 9: 34643479. https://doi.org/10.3390/app9173464

Xiaohui S, Li C, Bowen L, Jiawei L, Yingjun X, Yuzhong W (2018) Carbon Fibers Decorated by Polyelectrolyte Complexes Toward Their Epoxy Resin Composites with High Fire Safety. Chinese Journal of Polymer Science 36: 1375-1384. https://doi.org/10.1007/s10118-018-2164-1

Xin W, Lei S, Weiyi X, Hongdian L, Yuan H (2011) A effective flame retardantfor epoxy resins based on poly (DOPO substituted dihydroxyl phenyl pentaerythritol diphosphonate). Materials Chemistry and Physics 125: 536-541. https://doi.org/10.1016/j.matchemphys.2010.10.020

Xiaoyi H, Xiaoyun M, Huaitian B, Xiaoyuan Y, Gangbiao J, Minghua Z (2011) Chemical modification of chitosan by tetraethylenepentamine and adsorption study for anionic dye removal. Carbohydrate Research 346: 1232-1240. https://doi.org/10.1016/j.carres.2011.04.012

Xiaoyu C, Xiaodong G, Jun S, Sheng Z (2017) The effect of chitosan on the flammability and thermal stability of polylactic acid/ammonium polyphosphate biocomposites. Carbohydrate Polymer 157: 15861593. https://doi.org/10.1016/j.carbpol.2016.11.035

Xiaodong L, Xiaoyu G, Jun S, Sheng Z (2017) Preparation and characterization of chitosan derivatives and their application as flame retardants in thermoplastic polyurethane. Carbohydrate Polymers 167: 356-363. https://doi.org/10.1016/j.carbpol.2017.03.011

Xin W, Yuan H, Lei S, Hongyu Y, Weiyi X, Hongdian L (2011) Synthesis and characterization of a DOPOsubstituted organophosphorus oligomer and its application in flame retardant epoxy resins. Progress in Organic Coatings 71: 72-82. https://doi.org/10.1016/j.porgcoat.2010.12.013

Xin W, Yuan H, Lei S, Weiyi X, Hongdian L, Pin L, Ganxin J (2010) Flame retardancy and thermal degradation mechanism of epoxy resin composites based on a DOPO substituted organophosphorus oligomer. Polymer 51: 2435-2445. https://doi.org/10.1016/j.polymer.2010. 03.053 
Xin W, Yuan H, Lei S, Weiyi X, Hongdian L (2011) Thermal degradation mechanism of flame retarded epoxy resins with a DOPO-substitued organophosphorus oligomer by TG-FTIR and DP-MS -

ScienceDirect. Journal of Analytical and Applied Pyrolysis 92: 164-170. https://

doi.org/10.1016/j.jaap.2011.05.006

Xin W, Yuan H, Lei S, Weiyi X, Hongdian L (2011) Preparation, mechanical properties, and thermal degradation of flame retarded epoxy resins with an organophosphorus oligomer. Polymer Bulletin, 67: 859-873. https://doi.org/10.1007/s00289-011-0473-4

Xin W, Yuan H, Lei S, Weiyi X, Hongdian L, Pin L, Ganxin J (2010) Flame retardancy and thermal degradation mechanism of epoxy resin composites based on a DOPO substituted organophosphorus oligomer. Polymer 51(11): 2435-2445. https://doi.org/10.1016/j.polymer. $2010 . \quad 03.053$

Yun L, Quanquan W, Zhiming J, Chuanjie Z, Zhongfang L, Huaqi C, Ping Z (2018) Effect of chitosan on the fire retardancy and thermal degradation properties of coated cotton fabrics with sodium phytate and APTES by LBL assembly. J Anal Appl Pyrol 135: 289-298. https://doi.org/ 10.1016/j.jaap.2018.08.024

Zhi L, Alejandro JG, Vignesh BH, Deyi W (2018) Covalent assembly of MCM-41 nanospheres on graphene oxide for improving fire retardancy and mechanical property of epoxy resin. Compos B Eng 138: 101112. https://doi.org/10.1016/j.compositesb.2017.11.001

Zongmin Z, Ke S, Luoxin W, Junsheng W (2019) Synthesis of an effective bio-based flame-retardant curing agent and its application in epoxy resin: Curing behavior, thermal stability and flame retardancy. Polymer Degradation and Stability 167:179-188. https://doi.org/10.1016/j. polymdegradstab.2019.07.005

Zhiquan C, Juncheng J, Yuan Y, Gang C,Tingting C, Qingwu Z (2020) Layer-by-layer assembled bagasse to enhance the fire safety of epoxy resin: A renewable environmental friendly flame retardant. Appl Polym Sci 138: 50032-50046. https://doi.org/10.1002/app.50032

Zongmin Z, Panlong L, Hao W, Luoxin W, Bin Y, Feihua Y (2020) A facile one-step synthesis of highly efficient melamine salt reactive flame retardant for epoxy resin. Journal of Materials Science 55: 1283612847. https://doi.org/10.1007/s10853-020-04935-6

\section{Figures}



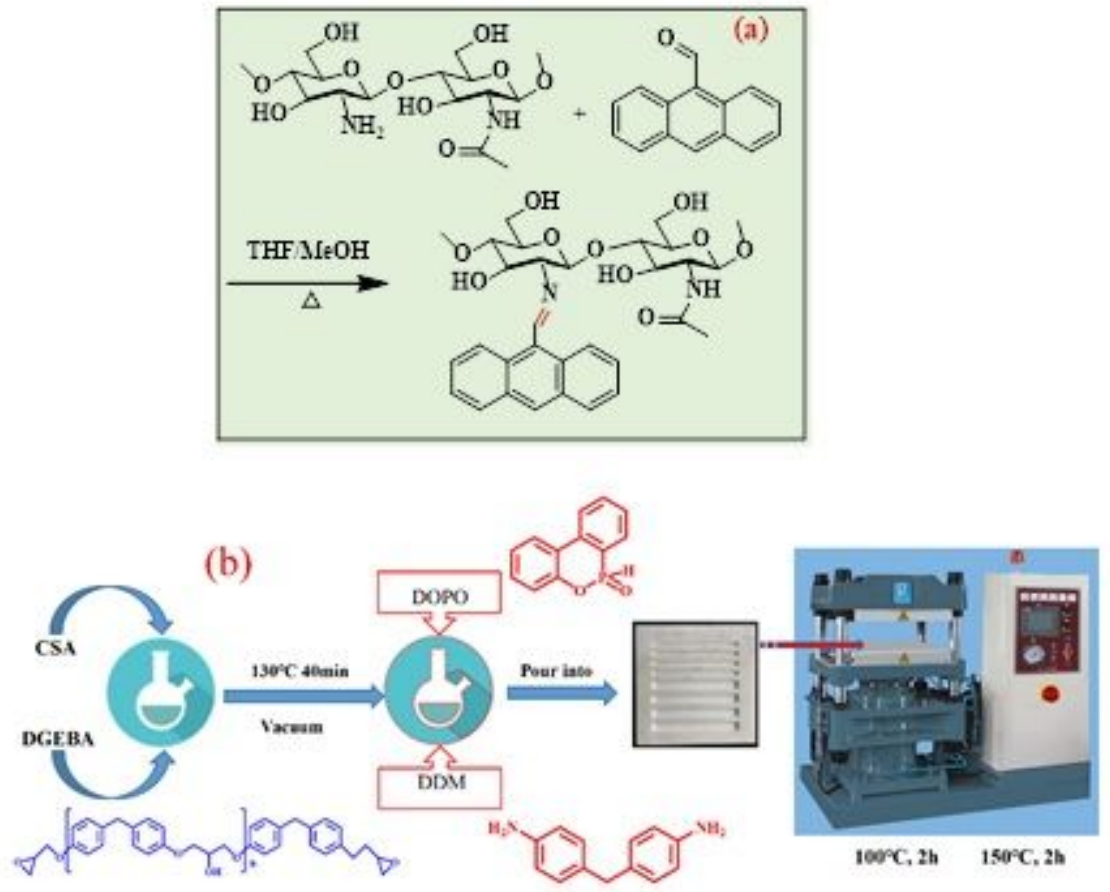

Figure 1

Schematic diagram of the synthetic route of CSA (a) and the preparation process of EP composites (b)

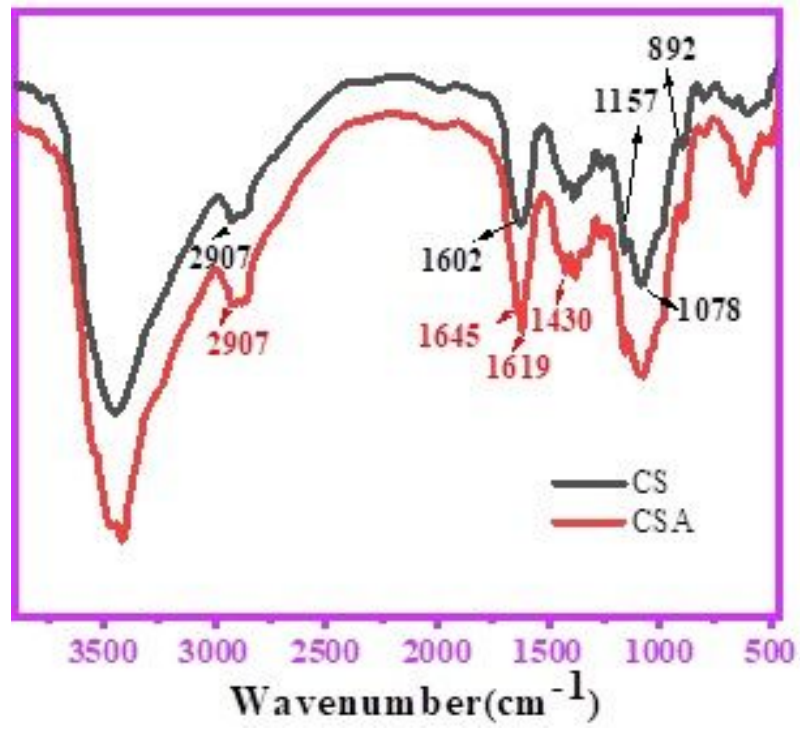

Figure 2

FTIR spectra of CS and CSA 

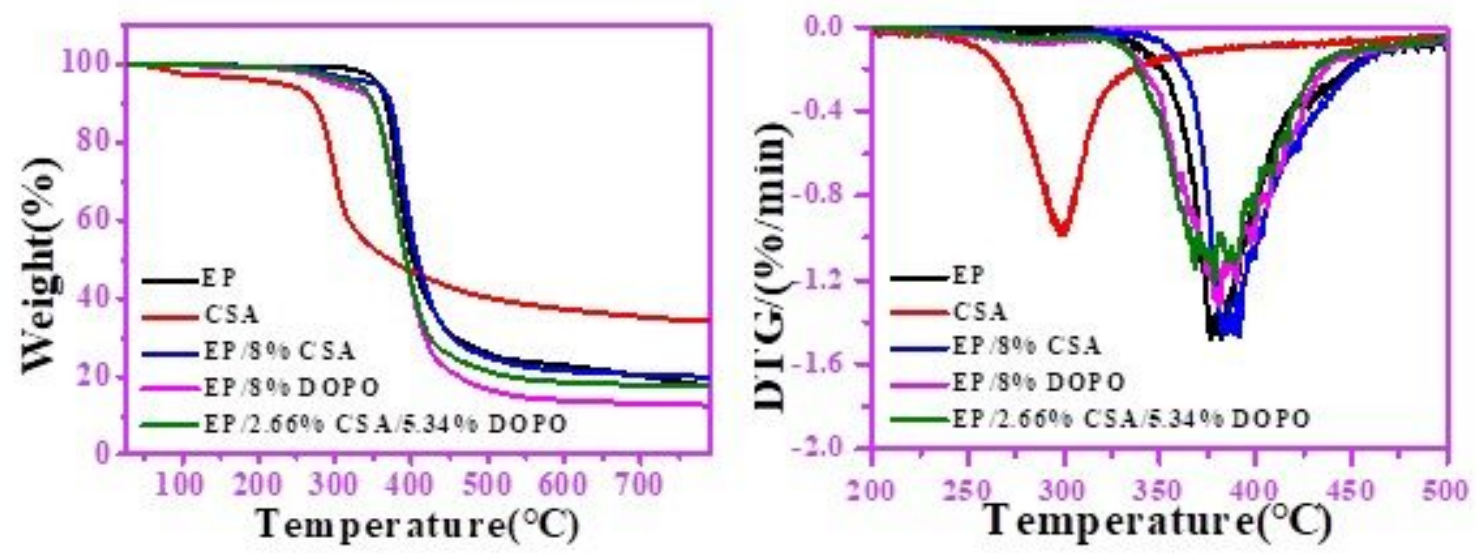

Figure 3

TGA curves and DTG curves of epoxy samples under N2 atmosphere
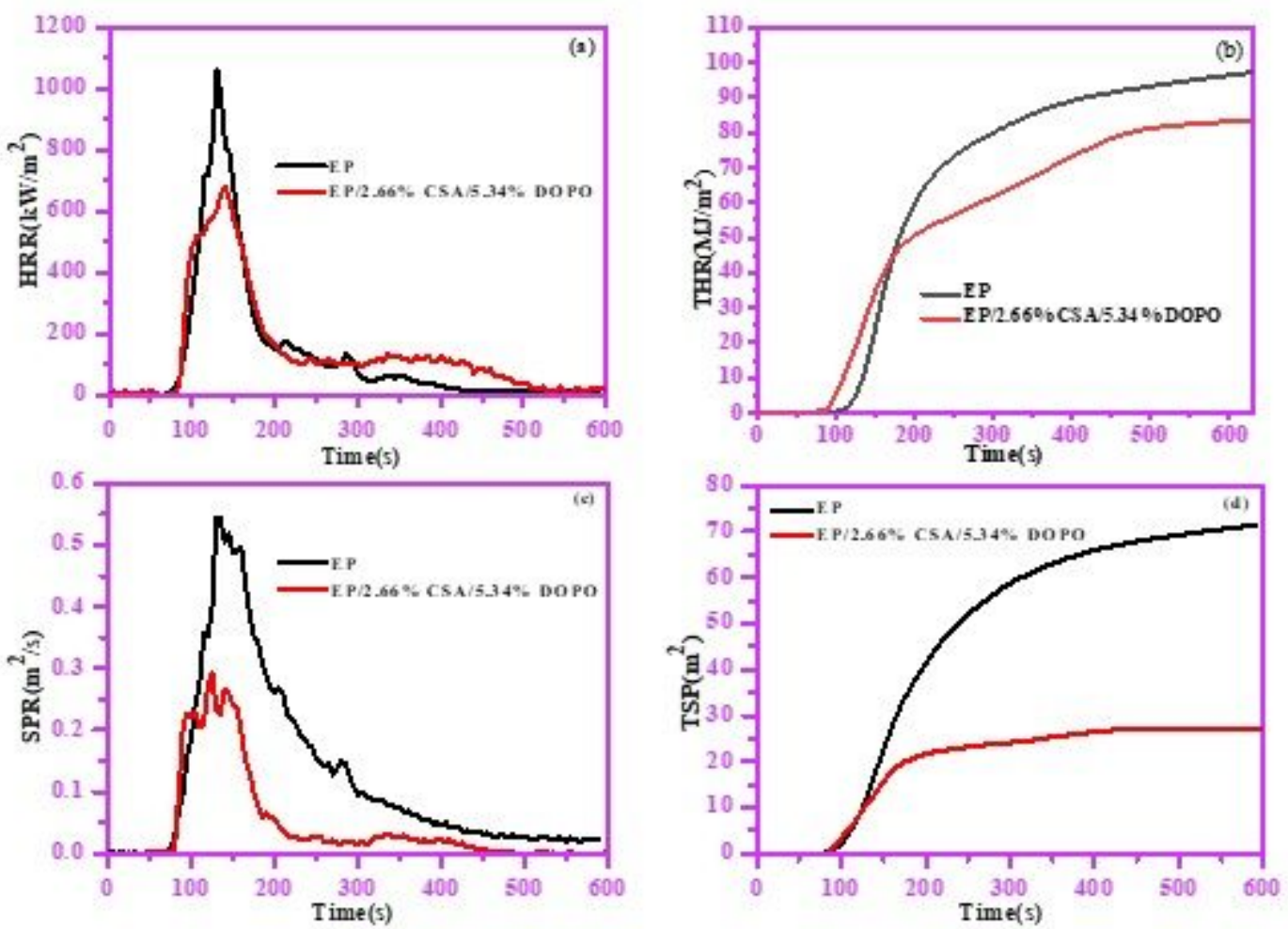

Figure 4

The curves of HRR (a), THR (b), SPR (c) and TSR (d) of EP and EP/2.66\%CSA/5.34\%DOPO 

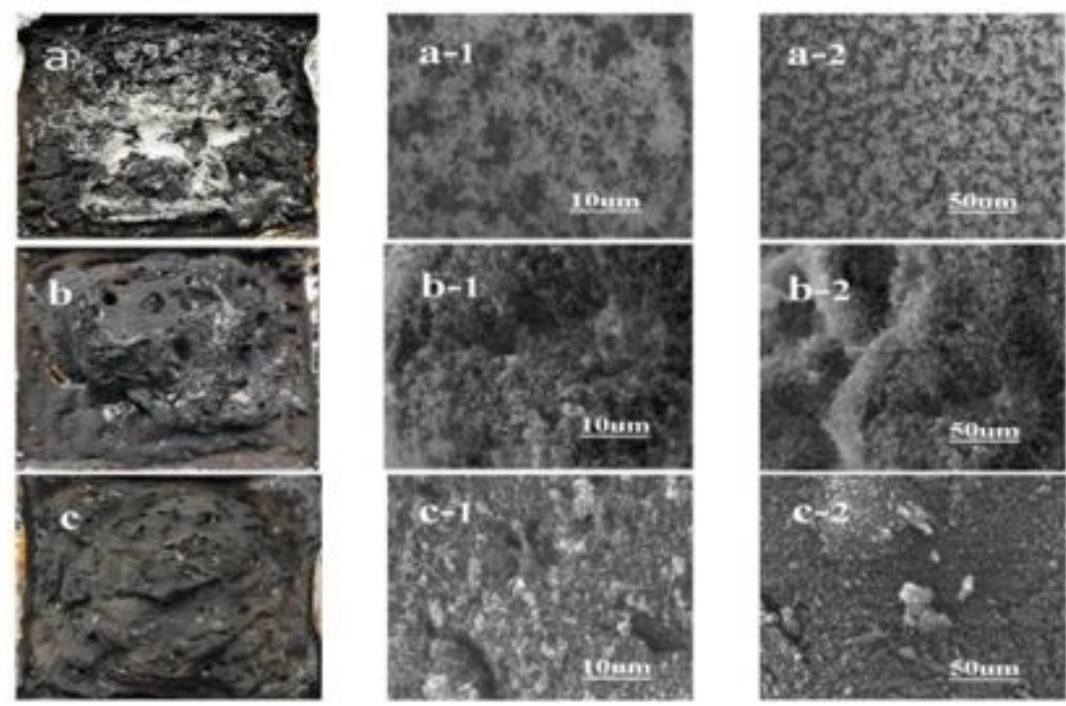

Figure 5

The digital and SEM images of the char residues from EP (a, a-1,a-2), EP/1.66\%CSA/3.35\%DOPO \b-1区b2】and EP/2.66\%CSA/5.34\%DOPO (c, c-1, c-2)
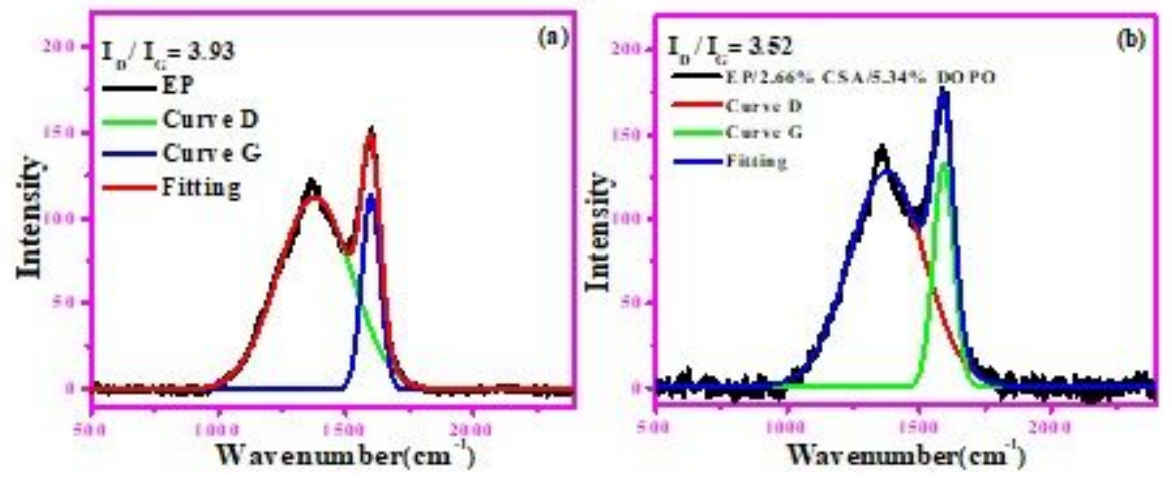

Figure 6

Raman spectra of char residues for EP (a) and EP/2.66\%CSA/5.34\%DOPO (b) 

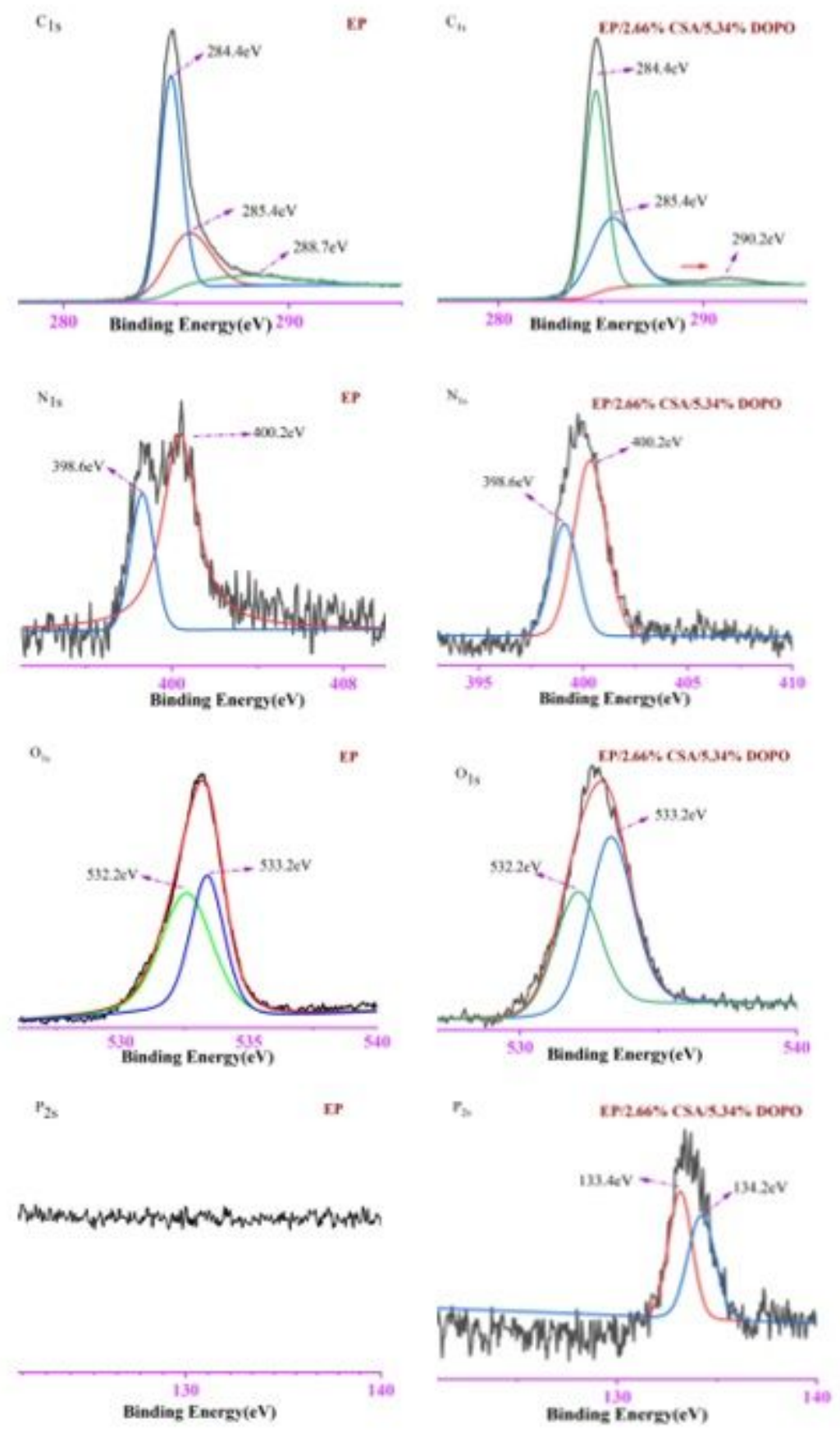

\section{Figure 7}

C1s, N1s, 01s and P2s spectra of char residues for EP and EP/2.66\%CSA/5.34\%DOPO 3.5 Py-GC/MS analysis of EP and EP/2.66\%CSA/5.34\%DOPO 


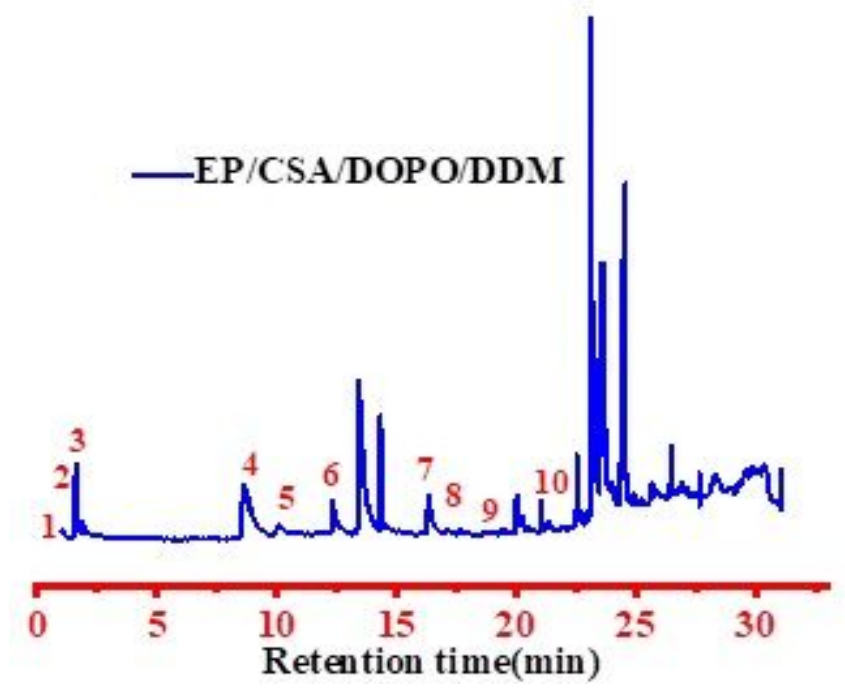

Figure 8

The gas chromatography spectrum of EP/2.66\%CSA/5.34\%DOPO sample
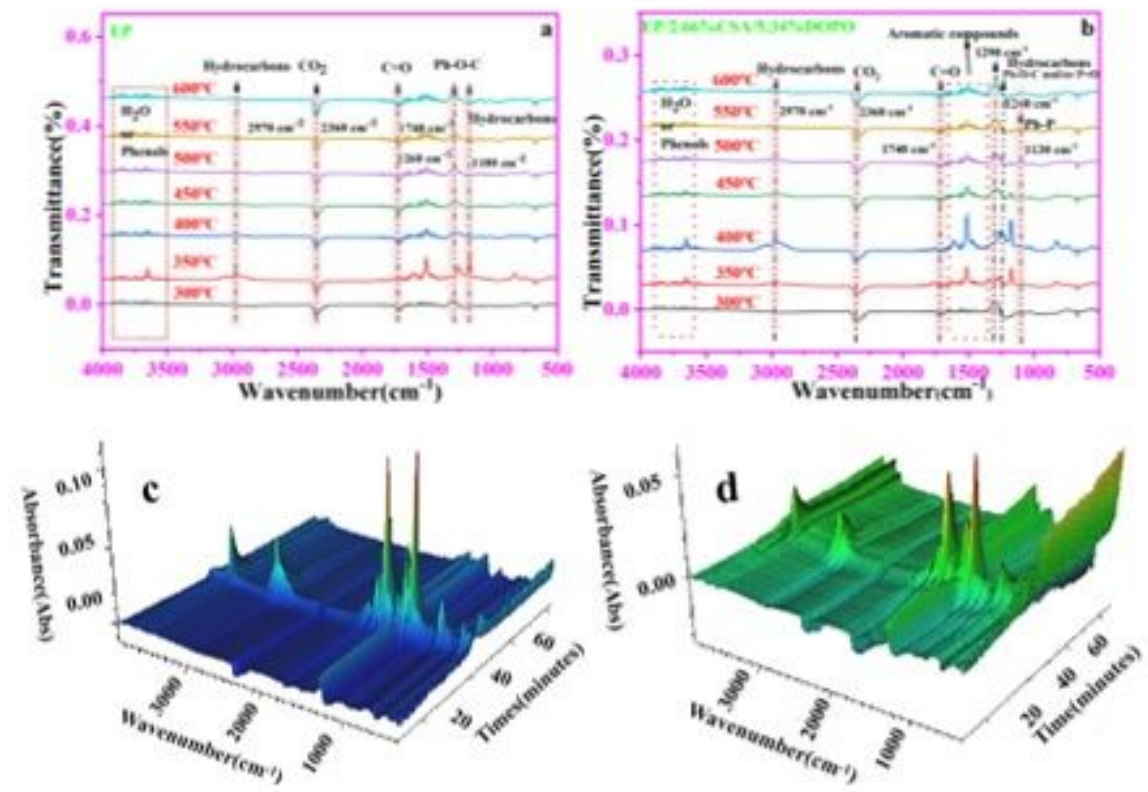

Figure 9

The real time FTIR spectra and 3D TG-FTIR images of EP $(a, c)$ and EP/2.66\%CSA/5.34\%DOPO $(b, d)$ samples at different pyrolysis temperature

\section{Supplementary Files}

This is a list of supplementary files associated with this preprint. Click to download.

- Scheme1.pdf

- SupplementaryMaterial.docx 